\title{
STUDY OF ENCAPSULATION PARAMETERS TO IMPROVE CONTENT OF LYCOPENE IN TOMATO (SOLANUM LYCOPERSICUM L.) POWDERS
}

\author{
J. Montiel-Ventura ${ }^{\text {b }}$ J.J. Luna-Guevara $A^{\mathrm{a}}$, M.A. Tornero-Campante ${ }^{\mathrm{b}}$, \\ A. Delgado-Alvarado ${ }^{b}$ and M.L. Luna-Guevara* ${ }^{a}$ \\ angeniería en Alimentos, Facultad de Ingeniería Química, Benemérita Universidad Autónoma de Puebla, 14 Sur y \\ Av. San Claudio, Ciudad Universitaria, Col. San Manuel, 72590, Puebla, Puebla. México \\ ${ }^{\mathrm{b}}$ Colegio de Postgraduados, Campus Puebla, Boulevard Forjadores de Puebla 25, CP 72760, Puebla, Puebla. \\ México
}

(Received: 12 February 2017; accepted: 18 September 2017)

The aim was to examine conditions of convective drying and spray-drying to improve preservation of lycopene content in tomatoes. The weight, size, colour, $\mathrm{pH}$ and ${ }^{\circ}$ Brix values were evaluated in fresh fruit (FF) and colour (L, a, b), hue, and chrome indices were analysed from dried tomatoes, too. Tomato paste was dried (40, 50, 60, and 80 ${ }^{\circ} \mathrm{C}$ with times of 540, 390, 270, and $240 \mathrm{~min}$ ) under convection conditions and pulverized. In the encapsulation treatments core material with tomato powders of 50,60 , and $70 \%$, shell solution of maltodextrin/gum arabic $1: 1$, flow rate of $4,6,9$, and $12 \mathrm{ml} \mathrm{min}^{-1}$, and inlet air $\mathrm{T}$ of 160,170 , and $180{ }^{\circ} \mathrm{C}$ were used. The physicochemical properties of FF corresponded to a degree of ripeness for consumption. The $\mathrm{a}, \mathrm{a} / \mathrm{b}$, and hue values of dried tomatoes at $50{ }^{\circ} \mathrm{C}$ significantly correlated to red colouring and higher lycopene content $(47.98 \pm 1.49 \mathrm{mg} / 100 \mathrm{~g})$. The encapsulation with $50 \%$ and $60 \%$ of tomato powders, $170{ }^{\circ} \mathrm{C}$ and $9 \mathrm{ml} \mathrm{min}^{-1}$ treatments increased lycopene contents to $10.41 \mathrm{mg} / 100 \mathrm{~g}, 10.20 \mathrm{mg} / 100 \mathrm{~g}$, and $11.51 \mathrm{mg} / 100 \mathrm{~g}$, respectively. The results demonstrated that the physicochemical and functional properties were influenced by drying conditions, providing useful information for increasing the stability of lycopene in dried tomatoes.

Keywords: lycopene, tomato drying, antioxidant, encapsulation

Tomato belonging to the family Solanaceae is considered an important vegetable, since it adds to the gastronomic variety and is included in our daily diet. Mexico is the leading exporter of tomatoes, its production is mainly directed to the United States. For this reason, it is recognized to be a crop of great socioeconomic importance (SAGARPA, 2015). Tomato is one of the main sources of minerals, vitamins, and antioxidants due to its lycopene content (LunA-GuEvara et al., 2014). Lycopene is a carotenoid found in certain fruit and vegetables, it is a liposoluble pigment responsible for the red-orange colour and it has outstanding antioxidant properties. Main sources of lycopene are tomato and its derivatives and other fruit, such as watermelon, cherry, pink grapefruit, pink guava, red pepper, and papaya (CANTRELl et al., 2003).

\footnotetext{
* To whom correspondence should be addressed. Phone: +52 01 (222) 29-55-00; fax: +52 01 (222) 29-55-00; e-mail: maria.luna@correo.buap.mx
}

This is an open-access article distributed under the terms of the Creative Commons Attribution-NonCommercial 4.0 International License (https://creativecommons.org/licenses/by-nc/4.0/), which permits unrestricted use, distribution, and reproduction in any medium for non-commercial purposes, provided the original author and source are credited, a link to the CC License is provided, and changes - if any - are indicated.

0139-3006 (c) 2018 The Author(s) 
Tomato is commonly marketed as a fresh vegetable; however, it is a highly perishable product due to its high water content, which limits its distribution. For this reason, several reports have been carried out oriented to its preservation, including dehydration in slices, cubes, and powder (MARIEM \& MABrouki, 2014). Convective drying is one of the most important preserving technologies used for fruit and vegetables, however changes and degradation of bioactive compounds depend on drying conditions (MirelES-ARRIAGA et al., 2016).

An alternative for preservation of the nutritional and bioactive properties is the use of microencapsulation, which is a technique that is applied to protect numerous solid, liquid, and gaseous ingredients from the environmental conditions, particularly the oxidation reactions caused by light or oxygen (Perez-Masia et al., 2015, Martinez-Hernandez et al., 2016). The goal of this study was to evaluate convective drying and spray-drying as alternatives to preserve lycopene content in tomatoes.

\section{Materials and methods}

\subsection{Raw material}

Fresh type tomatoes were selected by the following criteria: uniformity in size, insect-free, fresh appearance and firmness, the edible maturity was 6 (red) according to the colour chart of USDA (1997). Also, to guarantee ripeness of the fruit, the physicochemical properties, such as colour parameters a (green-red), b (blue-yellow), L (luminosity), indices a/b, hue, chroma, $\mathrm{pH}$ and ${ }^{\circ}$ Brix were evaluated, since vegetable matter in the ripened stage has the greatest lycopene content (LunA-GuEVARA et al., 2014).

\subsection{Obtaining of encapsulated tomato powders}

Since tomato has high water content (90-95\%), it was necessary to achieve higher solids concentration for spray-drying treatments.

1.2.1. Convective drying. Tomatoes were homogenized into paste form, which was uniformly spread and the start weight was recorded. Then, the samples were subjected to the drying treatments with temperatures $40,50,60$, and $80{ }^{\circ} \mathrm{C}$ using an oven (Binder, model FD53, Germany); these were weighed every 15 min during the first $2 \mathrm{~h}$ and every $30 \mathrm{~min}$ until reaching the constant weight. When equilibrium was assumed, the moisture content was determined at $105{ }^{\circ} \mathrm{C}$. The moisture content of the product was expressed as free moisture fraction $\Psi$ (the removable water portion remaining in the product) (Eq. 1).

$$
\Psi=\frac{X-X_{e}}{X_{o}-X_{e}}
$$

where $\Psi$ : free fraction moisture; $\mathrm{X}$ : initial moisture; $\mathrm{X}_{0}$ : moisture at different temperatures and $\mathrm{X}_{\mathrm{e}}$ : equilibrium moisture.

Dried tomatoes were pulverized in a coffee grinder (Krups, model: GX410011V, Mexico), all powders were sieved through a mesh of 420 microns, stored at room temperature in the dark. Lycopene contents were analysed $(\mathrm{mg} / 100 \mathrm{~g})$, and tomato powders with the highest concentrations of the antioxidant compound were selected for encapsulation treatments. 


\subsection{Lycopene analyses}

The extraction and quantification of the lycopene content was carried out from $0.05 \mathrm{~g}$ of dried product or $0.7 \mathrm{~g}$ of encapsulated powder, according to SADLER and co-workers (1990). To each sample, $18 \mathrm{ml}$ of solvent was added (hexane, acetone, and ethanol; in a 2:1:1 proportion), and they were vigorously shaken for approximately $15 \mathrm{~min}$. Non-polar phases were collected for the assessment of absorbance at $503 \mathrm{~nm}$.

\subsection{Spray-drying treatments}

1.4.1. Feed emulsions. Tomato powders $(50-70 \%)$ were used as core, maltodextrin $10 \mathrm{E}$ (Maltodex, Mexico) and gum arabic (C 740, E300 Boruka, Mexico) were utilized as score materials in a ratio 1:1. All materials were homogenized to form an aqueous solution with $12 \%$ of total soluble solids.

1.4.2. Spray drying process. The aqueous solutions were spray dried using a Prendo (Mexico) spray dryer according to the conditions mentioned in Table $1(\mathrm{~T} \times 1-\mathrm{T} \times 10)$, the encapsulated products were stored under room temperature and absence of sunlight.

Table 1. Encapsulation treatments with different contents of tomato powder, conditions, and process variables

\begin{tabular}{lll}
\hline Treatments & Variables & Process conditions \\
\hline $1,2,3,4$ & Flow rate & Inlet $\mathrm{T} 170{ }^{\circ} \mathrm{C}$ \\
& $4,6,9,12\left(\mathrm{ml} \mathrm{min}^{-1}\right)$ & Content of tomato powder $50 \%$ \\
$5,6,7$ & Inlet T $160,170,180\left({ }^{\circ} \mathrm{C}\right)$ & Flow rate $9 \mathrm{ml} \mathrm{min}^{-1}$ \\
& & Content of powder $50 \%$ \\
$8,9,10$ & Contents of powder $50,60,70(\%)$ & Inlet $\mathrm{T} 170{ }^{\circ} \mathrm{C}$ \\
& & Flow rate $9 \mathrm{ml} \mathrm{min}^{-1}$ \\
\hline
\end{tabular}

\subsection{Statistical analysis}

The effects of the drying and microencapsulation treatments were evaluated on the lycopene content. The data of each treatment were analysed according to a completely randomized design and analysis of variance (ANOVA), with $\alpha=0.05$. The significant differences among the mean values were determined through Tukey's mean comparison tests, using the Statistix software (Statistix 8.1).

\section{Results and discussion}

\subsection{Characteristics of the fresh fruit}

The variables weight, size, colour, $\mathrm{pH}$, and soluble solids ( ${ }^{\circ}$ Brix) are considered quality parameters of the fresh tomato; these physical characteristics are related to the acceptance in the market and nutritional value (Luna-Guevara et al., 2014; Martinez-Hernandez et al., 2016). In Table 2 , the mean values of the physical parameters of the fruit used in this research are shown. The fruit were classified as medium-size and category 7 according to the CODEX Stan 293-2007 (2007). The $\mathrm{pH}$ value 4.25 is considered optimal and recommended for ripened fruit (ANTHON et al., 2011). The relationship between acidity and sugar content is 
decisive in the flavour of the tomato (TURHAN \& ŞENIZ, 2009). Regarding soluble solids, SANTIAGO and co-workers (1998) reported that a value greater than or equal to $4.0^{\circ} \mathrm{Brix}$ is considered the optimum. In this research, a slightly lower value was obtained, providing less sweet taste to the fruit.

Table 2. Physicochemical properties and lycopene content of fresh fruit tomatoes

\begin{tabular}{|c|c|c|c|c|c|c|}
\hline & \multicolumn{6}{|c|}{ Physicochemical characteristics } \\
\hline & $\begin{array}{l}\text { Weight } \\
\text { (g) }\end{array}$ & $\begin{array}{c}\text { Equatorial } \\
\text { diameter }(\mathrm{cm})\end{array}$ & $\begin{array}{l}\text { Axial diameter } \\
(\mathrm{cm})\end{array}$ & $\mathrm{pH}$ & $\begin{array}{l}\text { Soluble } \\
\text { solids } \\
\left({ }^{\circ} \mathrm{Brix}\right)\end{array}$ & \\
\hline \multirow{3}{*}{$\begin{array}{l}\text { Average } \\
\text { values }\end{array}$} & $88.74 \pm 4.17$ & $5.83 \pm 0.34$ & $4.36 \pm 0.19$ & $4.33 \pm 0.17$ & $3.93 \pm$ & 0.12 \\
\hline & \multicolumn{6}{|c|}{ Parameters and indices of colour and lycopene } \\
\hline & $\mathrm{L}$ & a & $\mathrm{b}$ & Chroma & Hue & $\begin{array}{c}\text { Lycopene } \\
\text { (mg/kg } \\
\text { FW) }\end{array}$ \\
\hline $\begin{array}{l}\text { Average } \\
\text { values }\end{array}$ & $34.61 \pm 2.24$ & $30.20 \pm 1.38$ & $24.91 \pm 2.46$ & $39.19 \pm 2.11$ & $50.55 \pm 2.71$ & $14.25 \pm 2.5$ \\
\hline
\end{tabular}

Data expressed as average $n=3 \pm$ standard deviation

The colour development of tomatoes is an indicator of the maturity stage and quality in the market; the red colour is due to degradation of chlorophyll and synthesis of carotenoids (LOPEZ \& Gomez, 2004). The results for the colour and lycopene content obtained in this study are indicated in Table 2, the a value is a good indicator of red colour development and the degree of ripening in tomato, while parameter $\mathrm{b}$ shows yellow discoloration, both parameters are related to the lycopene and xanthophyll contents, respectively (BATU, 2004). According to the classification reported by ARIAS and co-workers (2000), the values L and a obtained in this research correspond to very ripe tomatoes, although the Hue parameter is for colour between orange and red.

\subsection{Drying characteristics}

Initial moisture of fresh tomatoes was $92.35 \pm 0.30 \%$. The kinetics of the moisture content loss of tomato samples was determined at temperatures of $40,50,60$, and $80^{\circ} \mathrm{C}$. The variation of the free fraction moisture $(\Psi)$ over time at different temperatures is given in Figure 2. The drying process is characterized by a progressive decreasing of moisture content with time obtaining $540,390,270$, and $240 \mathrm{~min}$ for $40,50,60$, and $80^{\circ} \mathrm{C}$, respectively, reaching a percentage of final moisture less than $15 \%$.

In Table 3, the results of the parameters of colour and lycopene content of the dried tomatoes are presented. Luminosity varied significantly depending on the drying temperature, the treatment at $80^{\circ} \mathrm{C}$ a decreased the value of $\mathrm{L}$, producing powders that are more opaque. Regarding parameter a, tomatoes treated at $50^{\circ} \mathrm{C}$ had more reddish tones. Parameter $\mathrm{b}$ varied inversely with the drying temperature (Table 3 ). Hue significantly correlated with $\mathrm{a} / \mathrm{b}$ $(\mathrm{r}=0.998)$; both indices are related to the reddish colouring of tomato (ARIAS et al., 2000). The intensity or saturation (Chroma) of colour increased at $50^{\circ} \mathrm{C}$, providing tomato powder with 
more purity. Likewise, chroma together with parameters a and b significantly correlated with lycopene content ( $\mathrm{r}=0.96,0.89$, and 0.83 , respectively).

Table 3. Colour parameters and contents of lycopene in dehydrated fruit at different temperatures

\begin{tabular}{lcccc}
\hline & \multicolumn{4}{c}{ Drying temperatures $\left({ }^{\circ} \mathrm{C}\right)$} \\
\cline { 2 - 5 } & 40 & 50 & 60 & 80 \\
\hline $\mathrm{L}$ & $41.87 \pm 0.19 \mathrm{c}$ & $45.84 \pm 0.21 \mathrm{~b}$ & $54.51 \pm 0.11 \mathrm{a}$ & $39.77 \pm 0.32 \mathrm{~d}$ \\
$\mathrm{a}$ & $33.40 \pm 0.63 \mathrm{bc}$ & $36.69 \pm 0.39 \mathrm{a}$ & $34.10 \pm 0.33 \mathrm{~b}$ & $32.58 \pm 0.76 \mathrm{c}$ \\
$\mathrm{b}$ & $20.18 \pm 0.21 \mathrm{a}$ & $19.82 \pm 0.09 \mathrm{a}$ & $18.35 \pm 1.51 \mathrm{ab}$ & $16.35 \pm 0.20 \mathrm{~b}$ \\
Hue & $58.86 \pm 0.72 \mathrm{~b}$ & $61.62 \pm 0.17 \mathrm{a}$ & $61.74 \pm 1.88 \mathrm{a}$ & $63.35 \pm 0.79 \mathrm{a}$ \\
Chroma & $39.02 \pm 0.44 \mathrm{~b}$ & $41.70 \pm 0.38 \mathrm{a}$ & $38.74 \pm 0.88 \mathrm{~b}$ & $36.46 \pm 0.61 \mathrm{c}$ \\
$\mathrm{a} / \mathrm{b}$ & $1.66 \pm 0.05 \mathrm{~b}$ & $1.85 \pm 0.01 \mathrm{ab}$ & $1.87 \pm 0.15 \mathrm{ab}$ & $1.99 \pm 0.07 \mathrm{a}$ \\
Lycopene $(\mathrm{mg} / 100 \mathrm{~g})$ & $44.25 \pm 0.48 \mathrm{ab}$ & $47.93 \pm 2.6 \mathrm{a}$ & $41.94 \pm 1.49 \mathrm{bc}$ & $39.99 \pm 0.90 \mathrm{c}$ \\
\hline
\end{tabular}

Data expressed as average $n=3 \pm$ standard deviation. Values in a column followed by the same lowercase letter indicate no significant difference between dried samples according to the Tukey's test $(\mathrm{P}<0.05)$.

According to KULJARACHANAN and co-workers (2009), drying time and temperature significantly affect bioactive compounds. This effect was also observed in this study, higher lycopene contents were obtained at drying temperatures of $50^{\circ} \mathrm{C}$ and $40{ }^{\circ} \mathrm{C}$; however, with the latter, drying time was $540 \mathrm{~min}$ (Fig. 1). The results obtained for lycopene content were similar to those obtained by KeRKHOFs and co-workers (2005), who found values of 45.6 to $59.2 \mathrm{mg} / 100 \mathrm{~g}$ using convective drying at $45^{\circ} \mathrm{C}$. Tomato powders obtained with dehydration treatment at $50{ }^{\circ} \mathrm{C}$, with the maximum lycopene contents, were selected to be used in encapsulation experiments.

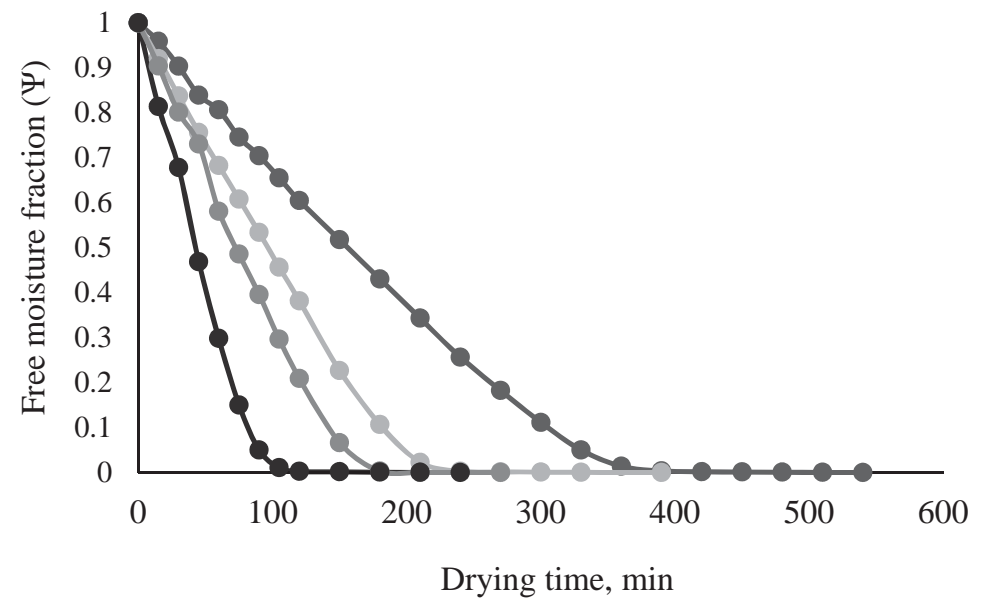

Fig. 1. Variation of the free moisture fraction $(\psi)$ with respect to time during the drying of tomato fruit at different temperatures

$\longrightarrow: 40^{\circ} \mathrm{C} ; \multimap: 50^{\circ} \mathrm{C} ; \multimap: 60^{\circ} \mathrm{C} ; \longrightarrow: 80^{\circ} \mathrm{C}$ 


\subsection{Encapsulation conditions}

There are several factors that influence core material stability, such as the flow rate, inlet air temperature, and shell materials. The variation in the flow rate of encapsulation treatments had a significant effect on lycopene content (Fig. 2), may be due to the fact that this parameter influences the internal temperature of the capsulate, and proper temperature values generate favourable conditions for the encapsulation of sensitive compounds such as lycopene (BERISTAIN et al., 2001). In encapsulated tomato lycopene content increased with a value of $11.51 \pm 0.15(\mathrm{mg} / 100 \mathrm{~g})$ at a flow rate of $9 \mathrm{ml} \mathrm{min}^{-1}$, while treatments $\mathrm{T} \times 2$ and $\mathrm{T} \times 4$ with flow rates of $6 \mathrm{ml} \mathrm{min}^{-1}$ and $12 \mathrm{ml} \mathrm{min}^{-1}$, respectively, caused no significant differences in the lycopene contents. These results are associated with droplet size and thickness of the capsules during spray-drying process, incorrectly chosen values enable lesser quantity tomato powder to be pulled into the encapsulate, resulting a reduction in the lycopene content. WANG and Chen (2006) used flow rates of 3 and $30 \mathrm{ml} \mathrm{min}{ }^{-1}$ and Nunes and Mercadante (2007) encapsulated tomato with lycopene contents of $2.8 \mathrm{mg} / 100 \mathrm{~g}$ and $10 \mathrm{mg} / 100 \mathrm{~g}$, which were lower and higher than those reported in this study. For spray-drying treatments it was observed that at inlet temperature $\mathrm{T} \times 6\left(170^{\circ} \mathrm{C}\right)$ the lycopene content was higher in comparison to $\mathrm{T} \times 7$ $\left(180{ }^{\circ} \mathrm{C}\right)$ with values of $10.41 \pm 0.06$ and $8.24 \pm 0.12 \mathrm{mg} / 100 \mathrm{~g}$, respectively. SHu and coworkers (2006) reported that an increase in the inlet $\mathrm{T}$ impedes the balance between the water evaporation rate and the formation of stable films, exposing the encapsulated material to high temperatures, and that is the reason why $T \times 7$ provided lower lycopene content. Likewise, AguiLAR-Rocha and co-workers (2012) observed a significant increase in the oxidation of lycopene when exposed to $180^{\circ} \mathrm{C}$ during spray-drying process.

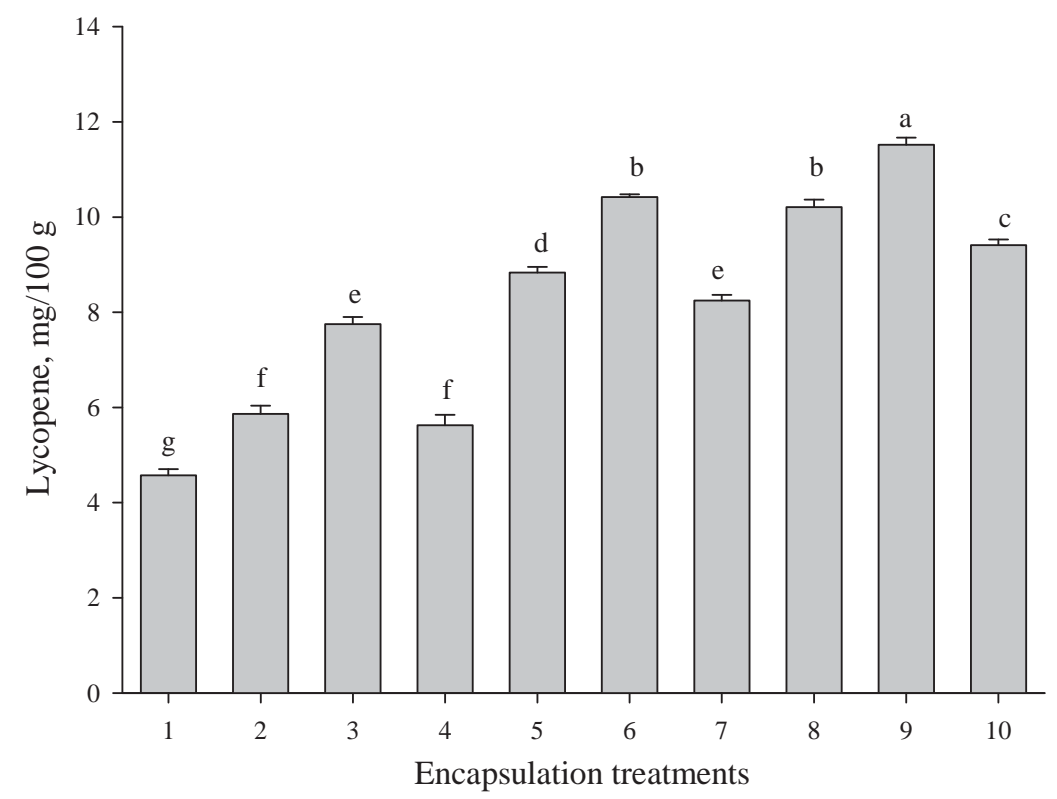

Fig. 2. Variation of lycopene contents of tomato powders with different encapsulation treatments. Data expressed as average $n=3 \pm$ standard deviation. Values with the same lowercase letter indicate no significant difference between treatments according to the Tukey's test $(\mathrm{P}<0.05)$ 
Finally, the quantity of tomato powder incorporated in the encapsulated solution also influences lycopene content, $\mathrm{T} \times 8(50 \%)$ and $\mathrm{T} \times 9(60 \%)$ reached the highest values of $10.20 \pm 0.16 \mathrm{mg} / 100 \mathrm{~g}$ and $11.51 \pm 0.15 \mathrm{mg} / 100 \mathrm{~g}$, respectively. While for $\mathrm{T} \times 10(70 \%)$ the lycopene content decreased, which is in agreement with findings of SHU and co-workers (2006) and Aguilar-Rocha and co-workers (2012), who reported that higher core amount (encapsulated material) reduces retention and encapsulation efficiencies, resulting in elevated degradation of bioactive compounds. Such results suggest that the principal factor for the preservation of lycopene is the conformation of more stable matrices and not the higher concentration of the tomato powder. Therefore, an increase in the quantity of tomato powder added to the emulsion decreases the proportion and the stability of encapsulating agents in the emulsion, determinant conditions for the formation of the microcapsules (DRUSCH \& MANNINO, 2009).

\section{Conclusions}

The results of this study demonstrated that tomato powder obtained at $50{ }^{\circ} \mathrm{C}$ and $390 \mathrm{~min}$ with conventional drying presented the highest content of lycopene and optimal colour parameters. By encapsulation with correctly selected parameters (tomato powder content, inlet temperature, and flow rate), microcapsules of tomato retained higher lycopene content. This technique could be utilised in various products to effectively prevent losses of valuable compounds.

\section{References}

Aguilar-Rocha, G., Favaro-Trindade, C.S. \& Ferreira-Grosso, C.R. (2012): Microencapsulation of lycopene by spray drying: Characterization, stability and application of microcapsules. Food Bioprod. Process., 90, 37-42.

Anthon, G.E., Lestrange, M. \& Barrett, D.M. (2011): Changes in pH, acids, sugars and other quality parameters during extended vine holding of ripe processing tomatoes. J. Sci. Food Agric., 91, 1175-1181.

Arias, R., Lee, T.C., Logendra, L. \& JANes, H. (2000): Correlation of lycopene measured by HPLC with the L*, a*, $\mathrm{b}^{*}$ color readings of a hydroponic tomato and the relationship of maturity with color and lycopene content, $J$. Agr. Food Chem., 48, 1697-1702.

Batu, A. (2004): Determination of acceptable firmness and colour values of tomatoes, J. Food Eng., 61, 471-475.

Beristain, C., Garcia, H. \& Vernon-Carter, E. (2001): Spray-dried encapsulation of cardamom (Elettaria cardamomum) essential oil with mesquite (Prosopis juliflora) gum. LWT - Food Sci. Technol., 34, 398-401.

Cantrell, A., McGarvey, D.J., Truscott, T.G., Rancan, F. \& Boehm, F. (2003): Singlet oxygen quenching by dietary carotenoids in a model membrane environment. Arch. Biochem. Biophys., 412, 47-54.

Codex Stan 293-2007 (2007): Norma para el tomate. (Standard for tomato.) Available at http://www.fao.org/faowhocodexalimentarius/shproxy/ru/?lnk=1\&url=https $\% 253 \mathrm{~A} \% 252 \mathrm{~F} \% 252 \mathrm{~F}$ workspace.fao.org $\% 252 \mathrm{Fsites} \% 2$ 52Fcodex\%252FStandards\%252FCODEX\%2BSTAN\%2B293-2008\%252FCXS_293s.pdf. (Last accessed: 12 May 2017).

Drusch, S. \& MANnino, S. (2009): Patent based review on industrial approaches for the microencapsulation of oils rich in polyunsaturated fatty acids. Trends Food Sci. Tech., 20, 237-244.

Hernandez-Rodriguez, J., Fernandez-Castillo, A., Quinto-Diez, P., Flores-Murrieta, F.E. \& Acosta-Olea, R. (2011): Estudio de la cinética de secado de jitomate (Solanum lycopersicum L.) (Study of tomato (Solanum lycopersicum L.) drying kinetics). Científica, 15, 125-130.

Kerkhofs, N.S., Lister, C.E. \&. Savage, G.P. (2005): Change in colour and antioxidant content of tomato cultivars following forced-air drying. Plant Food Hum. Nutr., 60, 117-121.

Kuljarachanan, T., Devahastin, S. \& Chiewchan, N. (2009): Evolution of antioxidant compounds in lime residues during drying. Food Chem., 113, 944-949.

Lopez, A.F. \& Gomez, P.A. (2004): Comparison of color indexes for tomato ripening. Hortic. Brasileira, 22, 534 537. 
Luna-Guevara, M.L., Jimenez-Gonzalez, O., Luna-Guevara, J.J., Hernandez-Carranza, P. \& Ochoa-Velasco, C.E. (2014): Quality parameters and bioactive compounds of red tomatoes (Solanum lycopersicum L.) cv Roma VF at different postharvest conditions. J. Food Res., 3, 1-11.

MARIEM, S.B. \& MABrouKI, S.B. (2014): Drying characteristics of tomato slices and mathematical modeling. IJEE, $4,17-24$.

Martinez-Hernandez, G.B., Boluda-Aguilar, M., Taboada-Rodriguez, A., Soto-Jover, S., Marin-Iniesta, F. \& Lopez-Gomez, A. (2016): Processing, packaging, and storage of tomato products: influence on the lycopene content. Food Eng. Rev., 8, 52-75.

Mireles-Arriaga, A.I., Ruiz-López, I.I., Hernández-García, P.A., Espinosa-Ayala, E., López-Martínez, L.X. \& Márquez-Molina, O. (2016): The impact of convective drying on the color, phenolic content and antioxidant capacity of noni (Morinda citrifolia L.). Food Sci. Technol. (Campinas), 36(4), 583-590.

Nunes, I.L. \& Mercadante, A.Z. (2007): Encapsulation of lycopene using spray-drying and molecular inclusion processes. Braz. Arch. Biol. Techn., 50, 893-900.

Perez-Masia, R., Lagaron, J.M. \& Lopez-Rubio, A. (2015): Morphology and stability of edible lycopene-containing micro and nanocapsules produced through electrospraying and spray drying. Food Bioprocess. Tech., 8, 459470.

SAdLeR, G., Davis, J. \& Dezman, D. (1990): Rapid extraction of lycopene and $\beta$-carotene from reconstituted tomato paste and pink grapefruit homogenates. J. Food Sci., 55, 1460-1461.

SAGARPA (2015): Comunicado di prensa Num. 466/15 Se consolida México como primer exportador mundial de tomate. (Press Release Num. 466/15 Mexico is consolidated as the world's leading tomato exporter.) Secretaria de Agricultura y Ganadería. Desarrollo Rural, Pesca y Alimentación July 2015. Available at http://www. sagarpa.gob.mx/saladeprensa/2012/2015/julio/Documents/2015B466.pdf. (Last accessed: 18 January 2017)

Santiago, J., Mendoza, M. \& Borrego, F. (1998): Evaluación de tomate (Lycopersicon esculentum Mill) en invernadero: Criterios fenológicos y fisiológicos. (Evaluation of tomato (Lycopersicon esculentum Mill) in greenhouse: Phenological and physiological criteria.) Agron. Mesoam., 9, 59-65.

Shu. B., Yu, W., Zhaо, Y. \& Liu, X. (2006): Study on microencapsulation of lycopene by spray drying. J. Food Eng., 76, 664-669.

Turhan, A. \& Şeniz, V. (2009): Estimation of certain chemical constituents of fruits of selected tomato genotypes grown in Turkey. Afr. J. Agric. Res., 4, 1086-1092.

USDA (1997): United States Standards for grades of fresh tomatoes. Available at: https://ucanr.edu/repository/view. cfm? article $=83755 \% 20$ \&groupid $=9$. (Last accessed: 23 Jun 2017).

WANG, C.Y. \& Chen, B.H. (2006): Tomato pulp as source for the production of lycopene powder containing high proportion of cis-isomers. Eur. Food Res. Technol., 222, 347-353. 